\title{
Palladium nanoparticle biosynthesis via Yerba Mate (Ilex paraguariensis) extract: an efficient eco-friendly catalyst for Suzuki-Miyaura reactions
}

\author{
Cristiane R. Schmitt ${ }^{1}$ Fábio A. Duarte ${ }^{2}$ Marcelo Godoi ${ }^{1}$. Carlos R. M. Peixoto ${ }^{1}$ - Fernanda Trombetta ${ }^{1}$ \\ Gilber R. Rosa' ${ }^{1}$
}

Received: 30 October 2020 / Accepted: 6 January 2021 / Published online: 1 February 2021

(c) The Author(s) 2021 OPEN

\begin{abstract}
This manuscript relates, for the first time, palladium nanoparticle production by bio-reduction using an llex paraguariensis aqueous extract. The solid obtained, PdISM, was used as a catalyst in Suzuki-Miyaura cross-coupling, composing a new eco-friendly, ligand-free, and low cost catalytic system. Excellent yields were obtained in the coupling of aryl iodides and bromides with phenylboronic acid. The same catalyst load was able to be recycled $3 x$.
\end{abstract}

Statement of Novelty The merit of the manuscript is based on the use of a plant (Ilex paraguariensis - yerba mate), which is produced on a large scale in South America for the preparation of teas, in the biogenic synthesis of palladium nanoparticle. The search for more sustainable routes in the production of metallic nanoparticle has grown exponentially in the last ten years and, for the plant in question, the literature only shows one study for the synthesis of silver nanoparticle. On the other hand, palladium nanoparticle have a wide application as catalysts in the reactions of organic synthesis and, to date, there is no study using yerba mate as a bio-reducer in the synthesis of such nanostructures.

Supplementary information The online version of this article contains supplementary material available at (https://doi.org/10.1007/ s42452-021-04167-6).

Gilber R. Rosa, gilberrosa@furg.br| ${ }^{1}$ Escola de Química E Alimentos, Universidade Federal Do Rio Grande, FURG, Campus Santo Antônio da Patrulha. Rua Barão Do Cahy, 125, Cidade Alta, Santo Antônio da Patrulha, RS CEP 95500-000, Brazil. ²Departamento de Química, Universidade Federal de Santa Maria-UFSM, Av. Roraima, 1000, Santa Maria, RS CEP 97105-900, Brazil. 


\section{Graphical Abstract}

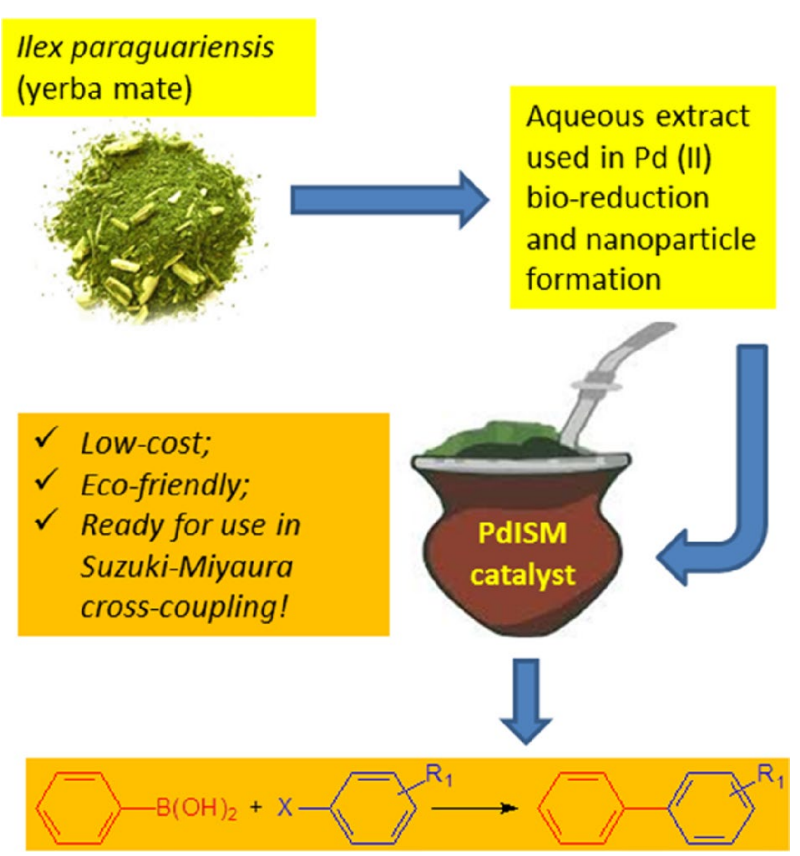

Keywords Palladium nanoparticle $\cdot$ Ilex paraguariensis · Bio-synthesis · Suzuki-Miyaura cross-coupling

\section{Introduction}

Modern organic synthesis, via cross-coupling reactions, makes use of catalysts to minimize the number of steps involved and increase the reaction yield [1]. In this scenario, the use of palladium nanoparticles (Pd NPs) as a catalyst generally yields excellent results compared to other catalytic precursors with the same metal [2]. Fixed on the Suzuki-Miyaura reaction [3], one of the most studied catalytic cross-couplings, the use of Pd NPs is shown in several ways: employing the isolated solid [4] and the solid supported on polymeric films [5], on carbon-derived supports [6], on a magnetic solid [7], on biomass waste [8], and others. However, Pd is expensive and therefore the synthesis of Pd NPs is also expensive. Trying to minimize the costs and complexity of Pd NPs production, some research papers have reported excellent results in the bio-reduction of Pd salts with plant extracts [9-14]. The Pd NPs obtained by this route were tested in cross-coupling reactions and proved successful as catalysts, thus promoting a more ecofriendly synthesis. In order to enhance local biomass, the plant llex paraguariensis (yerba mate), a native plant from South America, proved to be potentially interesting for bio-reduction of Pd salts as it was already active for the production of silver nanoparticle [15]. Also, yerba mate has a well-established production chain in the countries of Argentina, Brazil, Chile, Paraguay, Peru and Uruguay, due to its widespread use as tea [16], therefore, its acquisition is carried out in local commerce. The aqueous extract of yerba mate contains polyphenols, xanthines, alkaloids, flavonoids, vitamins and several minerals $[17,18]$, however, the reducing activity is attributed to the first two compounds listed [15, 19-21]. Given this scenario, in this paper we report, for the first time, the production of Pd NPs by bio-reduction using an Ilex paraguariensis aqueous extract. The technique used was innovative because it made use of sonication to avoid the agglomeration of nanometric structures. The solid, named PdISM, was produced at low cost and evaluated for Suzuki-Miyaura cross-coupling.

\section{Experimental section}

\subsection{Preparation of yerba mate aqueous extract}

The llex paraguariensis sample was purchased locally (Picolo brand, lot $04,340,818$ ) as it is a very widespread tea in the south of South America. In $10 \mathrm{~g}$ of sample were added $100 \mathrm{~mL}$ of deionized water. The mixture was placed in an $80^{\circ} \mathrm{C}$ thermostatic bath and stirred for $20 \mathrm{~min}$. 
Subsequently, it was filtered, and the solution obtained was centrifuged for use in the electrochemical measurements or preparation of Pd NPs.

\subsection{Electrochemical measurements}

Aqueous solutions of the extracts containing potassium chloride $(\mathrm{KCl}) 0.1 \mathrm{~mol} \mathrm{~L}^{-1}$ as supporting electrolyte, were prepared for the analysis in a potentiostat apparatus (Metrohm Autolab, model PGSTAT302N). Calibration curves were constructed using ascorbic acid solutions also in water containing $\mathrm{KCl} 0.1 \mathrm{~mol} \mathrm{~L}^{-1}$, and the antioxidant activity obtained by electrochemical methods were expressed in terms of equivalent of ascorbic acid. The cyclic voltammograms were obtained using scan rate $=0.100 \mathrm{~V} \mathrm{~s}^{-1}$. The total charge under the anodic waves and the peak currents of the background signal (solvent + supporting electrode) were subtracted from the total charges under the anodic waves, and peak currents obtained for each sample were measured within the range of 0.0 to $0.8 \mathrm{~V}$.

\subsection{Preparation of Pd NPs}

Pd NPs were obtained by bio-reduction of an $\mathrm{PdCl}_{2}$ aqueous solution with the llex paraguariensis aqueous extract by a sonication method (developed in this work). $1 \mathrm{mM}$ of $\mathrm{PdCl}_{2}$ aqueous solution was prepared to be added to the yerba mate aqueous extract (ratio: $10 \mathrm{~mL}$ of extract to $100 \mathrm{~mL}$ of $\mathrm{PdCl}_{2}$ solution). The reduction of the $\mathrm{PdCl}_{2}$ solution was accomplished by using the $100 \mathrm{~mL}$ of $1 \mathrm{mM}$ $\mathrm{PdCl}_{2}$ solution which was placed in a burette to be slowly dripped into a beaker containing $10 \mathrm{~mL}$ of the llex paraguariensis aqueous extract. The beaker was placed in an ultrasonic bath (Cole-Parmer 08,895-31, USA), the apparatus was switched on at room temperature and dripped at low speed ( 1 drop every $5 \mathrm{~s}$ ). After the addition of the $\mathrm{PdCl}_{2}$ solution was complete, the mixture remained under stirring in the apparatus for a further $24 \mathrm{~h}$. The solution was washed with acetone until the green color was removed, and it was centrifuged to give a black precipitate. Yield: $112 \mathrm{mg}$ of solid (PdISM).

\subsection{Transmission electron microscopy analysis (TEM)}

TEM analyses were performed using a JEOL JEM 1400 operated at $120 \mathrm{kV}$. The samples were prepared by deposition of the solid from an isopropanol suspension onto a carbon-coated copper grid at room temperature.

\subsection{X-ray diffraction (XRD) analysis}

The crystalline structure of the solid PdISM were obtained by X-ray diffraction (XRD) using a D500 Rigaku diffractometer (Siemens) operating at a scan rate of $0.05^{\circ} \mathrm{s}^{-1}$ in the range of $2 \theta=35-90^{\circ}$ using CuK $_{a}$ radiation (1.54056 $\AA$ ).

\subsection{Fourier transform infrared spectroscopy (FT-IR)}

FT-IR analysis was performed using a Shimadzu spectrophotometer (IR Prestige 21), combining 32 scans at a $2 \mathrm{~cm}^{-1}$ resolution. The sample was analysed as pellet with an approximate thickness and diameter of $2 \mathrm{~mm}$ and $5 \mathrm{~mm}$, respectively. The sample mass dilution was performed with $\mathrm{KBr}$.

\subsection{Inductively coupled plasma optical emission spectrometry (ICP-OES)}

A $50 \mathrm{mg}$ sample of the solid obtained by bio-reduction via llex paraguariensis aqueous extract was decomposed using $4 \mathrm{~mL}$ of $14.4 \mathrm{~mol} \mathrm{~L}^{-1} \mathrm{HNO}_{3}$ and heating to $100{ }^{\circ} \mathrm{C}$ (thermostatic bath), and was added to $10 \mathrm{~mL}$ with ultrapure water. The determination of metals in the sample was done by ICP-OES using a Spectro Ciros CCD (Spectro Analytical Instruments, Germany) simultaneous spectrometer equipped with a cross-flow pneumatic misting system, a double-step nebulization camera, and a quartz injector torch with $2.5 \mathrm{~mm}$ internal diameter. The plasma power was $1400 \mathrm{~W}$ and the argon flow rates were $14 \mathrm{~L} \mathrm{~min}^{-1}$ (plasma), $1 \mathrm{~L} \mathrm{~min}{ }^{-1}$ (nebulizer), and $1 \mathrm{~L} \mathrm{~min}^{-1}$ (auxiliary). The wavelengths for the determinations were as follows: Al $396.152 \mathrm{~nm}$, Ca $393.366 \mathrm{~nm}$, Cu $324.754 \mathrm{~nm}$, Fe $259.941 \mathrm{~nm}, \mathrm{~K} 766.491 \mathrm{~nm}, \mathrm{Mg} 285.213 \mathrm{~nm}, \mathrm{Mn}$ $257.611 \mathrm{~nm}, \mathrm{Na} 588.995 \mathrm{~nm}$, Ni $231.604 \mathrm{~nm}, \mathrm{P} 213.618 \mathrm{~nm}$, Pd 324.270 nm, S 182.034 nm, and Zn 206.191 nm.

\subsection{Suzuki-Miyaura cross-couplings}

\subsubsection{Experimental}

All reactions were conducted under a nitrogen atmosphere in a Schlenk reactor. Bases and solvents were purchased from Synth (Brazil). Phenylboronic acid and aryl halides were purchased from Sigma-Aldrich (Brazil). All chemicals were used without further purification. NMR spectra were recorded on a Bruker Ascend $400 \mathrm{MHz}$ spectrometer. Mass spectra were obtained on a GC/MS PerkinElmer Clarus $600 \mathrm{~T}$ (El, $70 \mathrm{eV}$ ) equipped with a $30 \mathrm{~m}$ capillary DB-5 column with a dimethylpolysiloxane stationary phase. Gas chromatography was performed on a 
PerkinElmer Clarus 400 GC equipped with a flame ionisation detector (FID) and a $30 \mathrm{~m}$ capillary column with a dimethylpolysiloxane stationary phase.

\subsubsection{Typical procedure for the Suzuki-Miyaura cross-coupling reaction}

A Schlenk reactor was charged with base ( $2 \mathrm{mmol})$, phenylboronic acid ( $187 \mathrm{mg}, 1.5 \mathrm{mmol})$, aryl halide $(1 \mathrm{mmol})$, $2 \mathrm{mg}$ of catalysts ( $\sim 0.5 \mathrm{~mol} \%$ of Pd using PdISM), undecane (internal standard, $10 \mu \mathrm{L})$, and solvent $(3 \mathrm{~mL})$. The reaction mixture was stirred at $100^{\circ} \mathrm{C}$ until complete. The solution was then allowed to cool to room temperature, taken up in ether $(20 \mathrm{~mL})$ and washed with aqueous $\mathrm{NaOH}$ $(1 \mathrm{M}, 5 \mathrm{~mL})$ and brine $(2 \times 5 \mathrm{~mL})$. The organic layer was dried over $\mathrm{MgSO}_{4}$, filtered, and concentrated in vacuum; then the crude material was purified by flash chromatography on silica gel. The corresponding biaryl products were characterised by ${ }^{1} \mathrm{H}$ and ${ }^{13} \mathrm{C}$ NMR, and by GC-MS.

4-Methylbiphenyl [5]. White solid. ${ }^{1} \mathrm{H}$ NMR $(400 \mathrm{MHz}$, $\left.\mathrm{CDCl}_{3}\right)$ $\delta: 7.58-7.56(\mathrm{~m}, 2 \mathrm{H}), 7.48(\mathrm{~d}, J=8.1 \mathrm{~Hz}, 2 \mathrm{H})$, 7.42-7.39 (m, 2H), 7.32-7.28 $(\mathrm{m}, 1 \mathrm{H}), 7.23(\mathrm{~d}, J=7.8 \mathrm{~Hz}$, $2 \mathrm{H}), 2.38(\mathrm{~s}, 3 \mathrm{H}) \mathrm{ppm} .{ }^{13} \mathrm{C} \mathrm{NMR}\left(100 \mathrm{MHz}, \mathrm{CDCl}_{3}\right) \delta: 141.1$, $138.3,137.0,129.4,128.7,127.0,126.9,21.1$ ppm. GC-MS (IE, $70 \mathrm{eV}) \mathrm{m} / \mathrm{z}$ (\%): 168 (100, M +), 167 (75), 165 (30), 152 (27), 153 (19), 83 (19), 82 (17), 169 (12).

4-Aminobiphenyl [24]. Orange solid. ${ }^{1} \mathrm{H}$ NMR $(400 \mathrm{MHz}$, $\left.\mathrm{CDCl}_{3}\right) \delta: 7.54-7.51(\mathrm{~d}, J=7,1 \mathrm{~Hz}, 2 \mathrm{H}), 7.42-7.36(\mathrm{~m}, 4 \mathrm{H})$, 7.27-7.23 (m, 1H), 6.74-6.71 (m, 2H), 3.66 (s, 2H) ppm. ${ }^{13} \mathrm{C}$ $\operatorname{NMR}\left(100 \mathrm{MHz}_{1} \mathrm{CDCl}_{3}\right) \delta: 145.8,141.1,131.5,128.6,127.9$, $126.3,126.2,115.3$ ppm. GC-MS (IE, $70 \mathrm{eV}$ ) m/z (\%): 169 $(100, M+), 168(20), 167(14), 170$ (13), 84 (12), 83 (11), 141 (10), 115 (9).

Biphenyl [5]. White solid. ${ }^{1} \mathrm{H}$ NMR $\left(400 \mathrm{MHz}, \mathrm{CDCl}_{3}\right) \delta$ : 7.59-7.57 (m, 4H), 7.44-7.40 (m, 4H), 7.34-7.31 (m, 2H) ppm. $\left.{ }^{13} \mathrm{C} \mathrm{NMR} \mathrm{(100} \mathrm{MHz,} \mathrm{CDCl}_{3}\right) \delta: 141.2,128.7,127.2$, 127.1 ppm. GC-MS (IE, $70 \mathrm{eV}) \mathrm{m} / \mathrm{z}(\%): 154(100, \mathrm{M}+), 153$ (43), 152 (29), 76 (19), 155 (12), 151 (9), 77 (9), 115 (7).

4-Cyanobiphenyl [5]. White solid. ${ }^{1} \mathrm{H}$ NMR $(400 \mathrm{MHz}$, $\left.\mathrm{CDCl}_{3}\right)$ 8: 7.72-7.66 (m, 4H), 7.59-7.56 (m, 2H), 7.50-7.39 (m, 3H) ppm. ${ }^{13} \mathrm{C}$ NMR $\left(100 \mathrm{MHz}, \mathrm{CDCl}_{3}\right) \delta: 145.6,139.1$, 132.5, 129.0, 128.6, 127.7, 127.2, 118.9, 110.8 ppm. GC-MS (IE, $70 \mathrm{eV}) \mathrm{m} / \mathrm{z}(\%): 179(100, \mathrm{M}+), 178(25), 151$ (17), 180 (14), 76 (14), 89 (11), 177 (8), 152 (8).

4-Methoxybiphenyl [5]. White solid. ${ }^{1} \mathrm{H}$ NMR $(400 \mathrm{MHz}$, $\left.\mathrm{CDCl}_{3}\right)$ 8: 7.56-7.51 (m, 4H), 7.43-7.39 (m, 2H), 7.31-7.28 $(\mathrm{m}, 1 \mathrm{H}), 6.97(\mathrm{~d}, J=8.8 \mathrm{~Hz}, 2 \mathrm{H}), 3.84(\mathrm{~s}, 3 \mathrm{H}) \mathrm{ppm} .{ }^{13} \mathrm{C} \mathrm{NMR}$

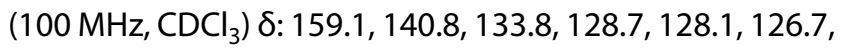
126.6, 114.2, 55.3 ppm. GC-MS (IE, $70 \mathrm{eV}) \mathrm{m} / \mathrm{z}(\%): 184$ (100, M +), 141 (69), 169 (68), 115 (53), 139 (19), 185 (17), $76(13), 63$ (12).

4-Nitrobiphenyl [5]. Brown solid. ${ }^{1} \mathrm{H}$ NMR $(400 \mathrm{MHz}$, $\left.\mathrm{CDCl}_{3}\right) \delta: 8.30(\mathrm{~d}, J=9.0 \mathrm{~Hz}, 2 \mathrm{H}), 7.74(\mathrm{~d}, J=9.0 \mathrm{~Hz}, 2 \mathrm{H})$,
7.64-7.61 (m, 2H), 7.52-7.43 (m, 3H) ppm. ${ }^{13} \mathrm{C}$ NMR $\left(100 \mathrm{MHz}_{1} \mathrm{CDCl}_{3}\right)$ 8: 147.6, 147.1, 138.8, 129.2, 128.9, 127.8, 127.4, 124.1 ppm. GC-MS (IE, $70 \mathrm{eV}) \mathrm{m} / \mathrm{z}(\%): 152$ (100), 199 (58, M+), 169 (53), 151 (34), 141 (24), 153 (22), 115 (17), 76 (15).

\section{Results and discussion}

Initially, the verification of the reducing activity of the aqueous extract of yerba mate was evaluated by cyclic voltammetry in different concentrations (Fig. 1).

In Fig. 1 it is observed that the llex paraguariensis extract shows an oxidation peak in the range of $0.40-0.70 \mathrm{~V}$, indicating the presence of reducing substances. Also, the increase of the anodic peak currents can be observed as a function of the higher concentration of the extract. In this case, ascorbic acid was used as the standard antioxidant, for which cyclic voltammograms were obtained for solutions in different concentrations. Ascorbic acid presented oxidation peak at $0.47 \mathrm{~V}$, and the currents obtained presented linearity as a function of the concentration according to the equation [Ascorbic Acid] $=20,695.85$ lap +0.00103 (lap = anodic peak current, in Amperes), in the concentration range of 0.0 to $0.5 \mathrm{mg} \mathrm{mL}^{-1}$, with $\mathrm{R}^{2}=0.9962$. Using the calibration curve to determine the total antioxidant activity of the stock solution of Ilex paraguariensis extract $(1 \mathrm{mg} / 10 \mathrm{~mL})$, antioxidant activity equivalent to $3.45 \mathrm{mg}$ of ascorbic acid per milliliter.

After confirming the reducing activity of the aqueous extract of yerba mate, the study continued with the production of Pd NPs. For this, a solution of $\mathrm{PdCl}_{2}$ was slowly added to the aqueous extract of yerba mate by a

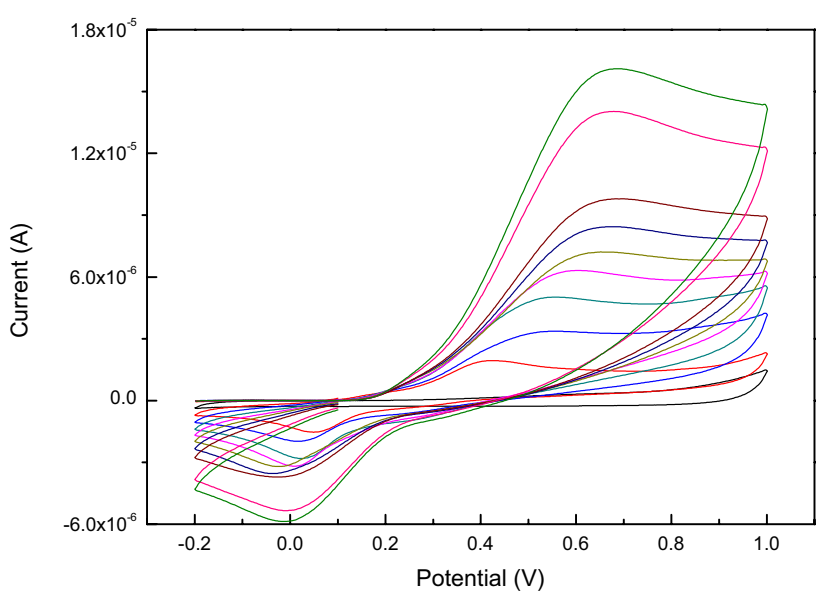

Fig. 1 Cyclic voltammograms of aqueous solutions of the aqueous extract of yerba mate at concentrations of $0.00,1.00,1.96,2.91$, $3.84,4.76,5.66,7.40,9.09$, and $10.71 \mathrm{mg} \mathrm{mL}^{-1}$, in $\mathrm{KCl} 0.1 \mathrm{~mol} \mathrm{~L}^{-1}$, sweep speed $=100 \mathrm{mV} \mathrm{s}^{-1}$ 

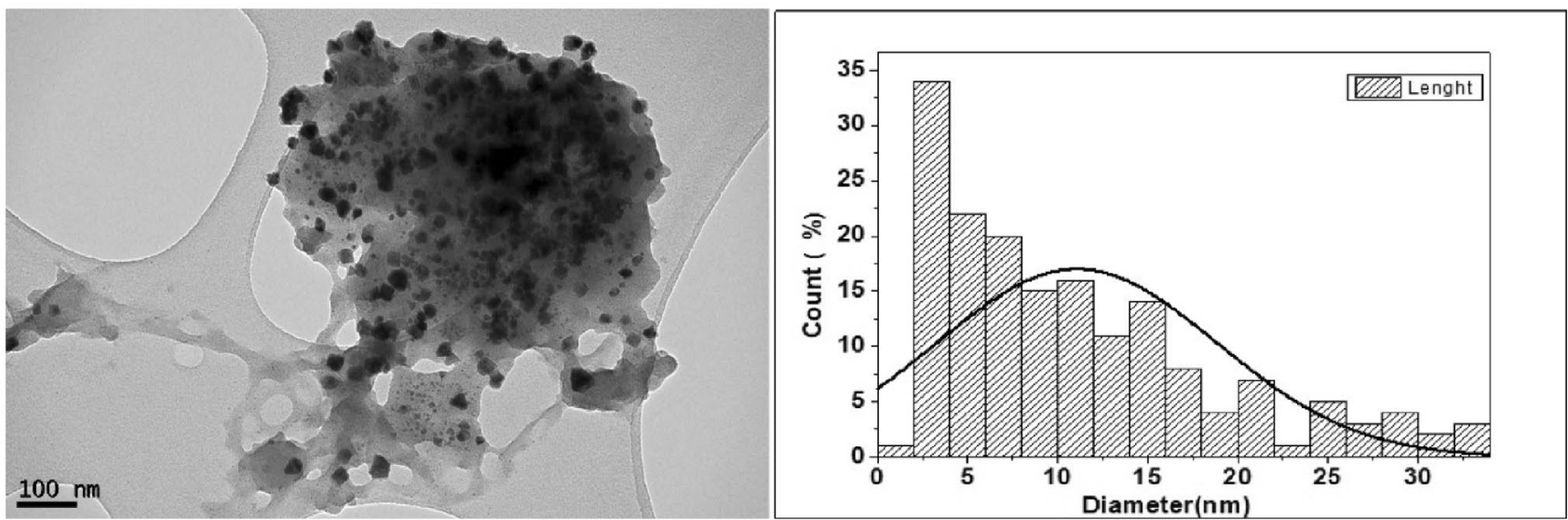

Fig. 2 TEM micrograph of the solid PdISM (left) and a histogram (right) illustrating the particle size distribution

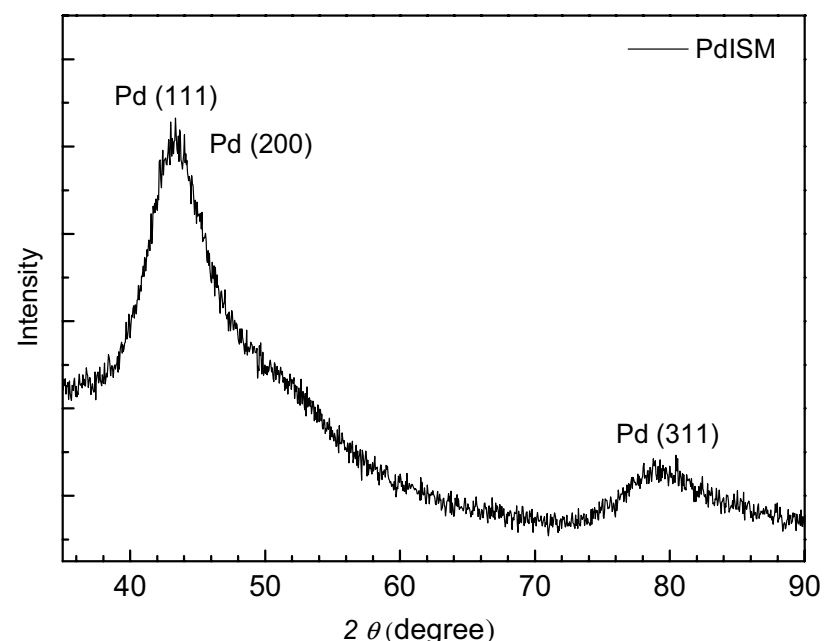

Fig. 3 X-ray diffractogram of the PdISM catalyst

sonication method (see Experimental section). The gradual color change of the solution from reddish orange to black indicated the formation of Pd NPs. After purification of the obtained solid, it was called PdISM and properly characterized. PdISM was evaluated by TEM indicating nanostructures (Fig. 2).

Figure 2 illustrates that sonication avoids total agglomeration of nanostructures, resulting in diameters compatible with other publications dealing with bio-reduction of palladium [8-14, 22]. Continuing the characterization of the solid, the crystalline nature of the PdISM catalyst was determined using XRD (Fig. 3).

Figure 3 shows the characteristic peaks of $\mathrm{Pd}$, being a face-centred cubic (fcc) structure similar to other studies involving Pd NPs bio-synthesis $[9,11,13,23]$. The diffractogram shows considerably wide peaks, which is a good indication of the nanometric characteristic of crystals

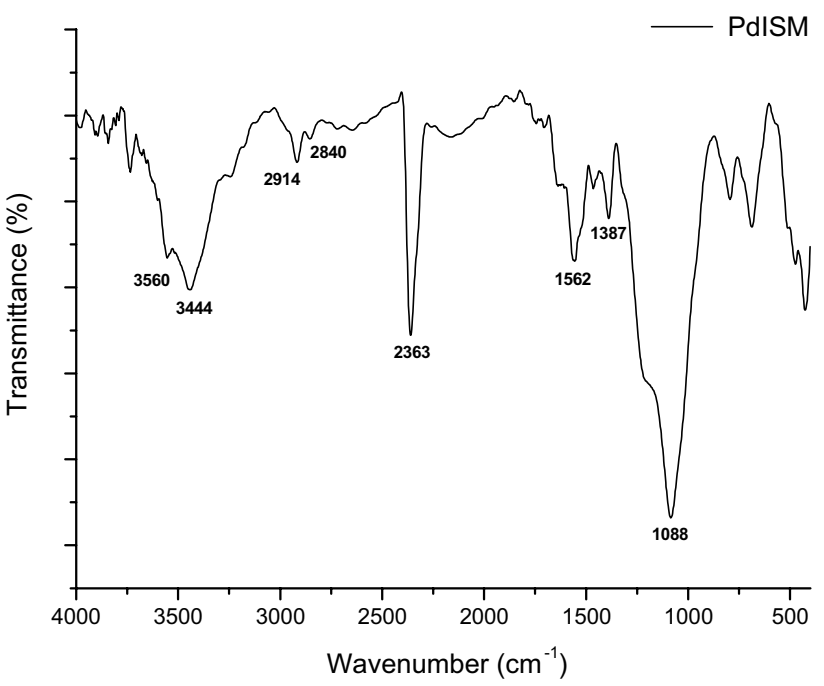

Fig. 4 FT-IR spectrum of PdISM catalyst

or crystallites. The Pd peaks corresponding to the (111) and (200) planes, which are coupled, and the (311) plane appear in the diffractogram (JCPDS $N^{\circ} 89-4897$ ). It is possible that this sample also contains $\mathrm{Pd}, \mathrm{Mg}$ and $\mathrm{Mn}$ oxides/ hydroxides, elements in greater concentration in the solid PdISM.

Following the investigation, the FT-IR analysis was conducted in order to assess the presence of organic compounds from the yerba mate linked to PdISM (Fig. 4).

Figure 4 shows that the PdISM has FT-IR spectrum similar to the aqueous extract of yerba mate obtained by Arreche and coworkers [15]. The obtained bands can be correlated to the compounds present in the plant extract, mainly polyphenols and xanthines: hydroxyls groups (3560-3544 $\left.\mathrm{cm}^{-1}\right)$, aliphatic C-H bonds $\left(2914-2840 \mathrm{~cm}^{-1}\right)$, carbonyl group $\left(1562 \mathrm{~cm}^{-1}\right), \delta_{\mathrm{C}-\mathrm{C}-\mathrm{H}}\left(1387 \mathrm{~cm}^{-1}\right)$, and $\mathrm{u}_{\mathrm{C}-\mathrm{O}}$ $\left(1088 \mathrm{~cm}^{-1}\right)$. The band observed at $2363 \mathrm{~cm}^{-1}$ indicates 
a possible contamination of the sample by $\mathrm{CO}_{2}$ during the FT-IR analysis. Thus, based on the FT-IR data, it can be inferred that the phenolic hydroxyl groups present in the extract of yerba mate play an important role in the reduction of $\mathrm{Pd}(\mathrm{II})$ cations and $[9,11,13,23]$, together with the carbonyl groups, has a possible action consortium in the stabilization of Pd NPs [24].

ICP-OES analysis was also performed on the prepared PdISM sample, and it showed that only $29 \%$ of the weight was formed by Pd. This result was consistent with the literature [23]. To better elucidate the composition of PdISM, a scan of other elements was performed (Table 1).

Table 1 showed that the composition of PdISM found is very similar to the composition of Ilex paraguariensis determined in dry leaves marketed for the preparation of teas [21].

Thus, with the actual knowledge about the composition of PdISM, the catalytic activity of the solid obtained was tested in the Suzuki-Miyaura reaction of phenylboronic acid with 4-bromotoluene (Scheme1, Table 2). The catalytic systems employed were guided by previous work of our research group and excelled by the use of the eco-friendly reagents [24-26].

The results outlined in Table 2 indicate that the best result (entry $3^{\mathrm{a}}$ ) was obtained when $\mathrm{K}_{2} \mathrm{CO}_{3}$ was used as the base and ethanol as the solvent. Reaction yield decreased with reduction of catalyst amount (entry $3^{\text {b }}$ ), temperature (entry $3^{\mathrm{c}}$ ), and reaction time (entry $3^{\mathrm{d}}$ ), showing that the reaction conditions of entry $3^{\mathrm{a}}$ are optimized. On the other hand, the PdISM catalyst did not tolerate apolar solvents like dioxane

Table 1 Results for determination of other elements in the PdISM sample by ICP-OES

\begin{tabular}{llll}
\hline Entry & Element & $\begin{array}{l}\text { Concentration }(\mu \mathrm{g} \\
\left.\mathrm{g}^{-1}\right)\end{array}$ & $\begin{array}{l}\text { Standard devia- } \\
\text { tion }\left( \pm \mu \mathrm{g} \mathrm{g}^{-1}\right)\end{array}$ \\
\hline 1 & $\mathrm{Al}$ & 1187 & 32 \\
2 & $\mathrm{Ca}$ & 8213 & 324 \\
3 & $\mathrm{Cu}$ & 66.3 & 1.7 \\
4 & $\mathrm{Fe}$ & 1257 & 25 \\
5 & $\mathrm{~K}$ & 6155 & 157 \\
6 & $\mathrm{Mg}$ & 16,930 & 282 \\
7 & $\mathrm{Mn}$ & 4102 & 22 \\
8 & $\mathrm{Na}$ & 391 & 10 \\
9 & $\mathrm{Ni}$ & 50.2 & 3.1 \\
10 & $\mathrm{~S}$ & 2913 & 86 \\
11 & $\mathrm{Zn}$ & 248 & 3 \\
\hline
\end{tabular}

Table 2 Optimization of reaction conditions for the SuzukiMiyaura cross-coupling of PdISM with phenylboronic acid and 4-bromotoluene ${ }^{a}$

\begin{tabular}{llll}
\hline Entry & Solvent & Base & Yield (\%) \\
\hline 1 & Ethanol & $\mathrm{K}_{3} \mathrm{PO}_{4}$ & 69 \\
2 & Ethanol & $\mathrm{CsF}$ & 53 \\
3 & $\mathrm{~K}_{2} \mathrm{CO}_{3}$ & $97(95)$ \\
& & $66^{\mathrm{b}}$ \\
& & & $41^{\mathrm{c}}$ \\
& & & $70^{\mathrm{d}}$ \\
4 & & $\mathrm{~K}_{3} \mathrm{PO}_{4}$ & 29 \\
5 & Dioxane & $\mathrm{CsF}^{\mathrm{e}}$ & 31 \\
6 & Dioxane & $\mathrm{K}_{2} \mathrm{CO}_{3}$ & 42 \\
8 & Dioxane & $\mathrm{K}_{3} \mathrm{PO}_{4}$ & 55 \\
9 & DMF & $\mathrm{CsF}$ & 58 \\
\hline
\end{tabular}

a Reaction conditions: 4-bromotoluene $(1 \mathrm{mmol})$, phenylboronic acid ( $1.5 \mathrm{mmol})$, PdISM catalyst $(2 \mathrm{mg}, 0.5 \mathrm{~mol} \%$ of Pd), base $(2 \mathrm{mmol})$, solvent $(3 \mathrm{~mL})$, undecane $(10 \mu \mathrm{L}), 24 \mathrm{~h}, 100{ }^{\circ} \mathrm{C}$, yields determined by GC (average of two runs). The isolated yield is stated in parentheses

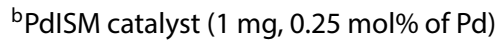

${ }^{\mathrm{C}}$ Temperature $=50^{\circ} \mathrm{C}$

${ }^{\mathrm{d}}$ Time $=16 \mathrm{~h} .{ }^{\mathrm{e}}$ Without catalyst

(entries 4-6), and the use of DMF yielded only modest results (entries 7-9). The result obtained with PdISM catalyst was successful, and represented a Suzuki-Miyaura cross-coupling reaction that was free of phosphine ligands and quaternary ammonium salts. The catalytic system is sustainable due to the "green" method of obtaining PdISM as well as the use of eco-friendly reagents (ethanol and $\mathrm{K}_{2} \mathrm{CO}_{3}$ ). When the same reaction was repeated without catalyst (entry $3^{\mathrm{e}}$ ), obviously, no formation of 4-methylbiphenyl was observed. These data confirmed the catalytic efficiency of PdISM.

With the actual knowledge about the composition of PdISM, the scope of its use in the Suzuki-Miyaura reaction was increased by varying aryl halides and/or functional groups on the aromatic ring (Table 3 ).

Table 3 shows the efficiency of PdISM in the development of a catalytic system for Suzuki-Miyaura cross-coupling without auxiliary ligands. Excellent yields for the coupling of aryl iodides were observed in extremely short reaction times; for example, the coupling reaction of phenylboronic acid with 4-iodoaniline occurred in only 15 min (entry 1 ). The catalytic system tolerated both electron-donating and electron-withdrawing groups on the aromatic ring (para position) of the
Scheme 1. The SuzukiMiyaura cross-coupling reaction investigated in this study
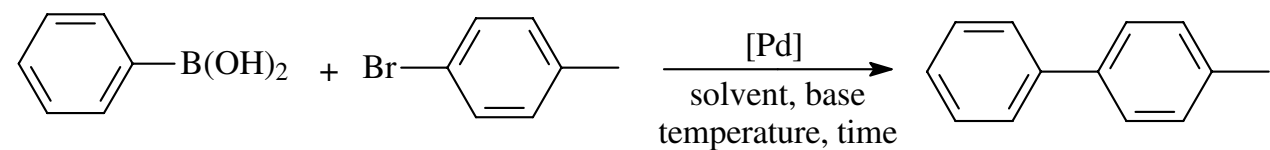
Table 3 Suzuki-Miyaura cross-coupling of phenylboronic acid with different aryl halides catalyzed by PdISM ${ }^{\mathrm{a}}$

\begin{tabular}{llllll}
\hline Entry & ArX & Time (h) & Yield (\%) & TON & TOF \\
\hline 1 & $4-\mathrm{H}_{2} \mathrm{NC}_{6} \mathrm{H}_{4} \mathrm{I}$ & 0.25 & 99 & 198 & 792 \\
2 & $\mathrm{Phl}$ & 1 & 96 & 192 & 192 \\
3 & $4-\mathrm{MeC}_{6} \mathrm{H}_{4} \mathrm{I}$ & 1 & 94 & 188 & 188 \\
4 & $4-\mathrm{NCC}_{6} \mathrm{H}_{4} \mathrm{Br}$ & 20 & 93 & 186 & 9 \\
5 & $\mathrm{PhBr}$ & 24 & 99 & 198 & 8 \\
6 & $4-\mathrm{MeC}_{6} \mathrm{H}_{4} \mathrm{Br}$ & 24 & 97 & 194 & 8 \\
& & & $35^{\text {b }}$ & 70 & 3 \\
7 & $4-\mathrm{MeOC}_{6} \mathrm{H}_{4} \mathrm{Br}$ & 24 & 91 & 182 & 8 \\
8 & $4-\mathrm{O}_{2} \mathrm{NC}_{6} \mathrm{H}_{4} \mathrm{Cl}$ & 24 & 11 & 22 & 1 \\
9 & $4-\mathrm{F}_{3} \mathrm{CC}_{6} \mathrm{H}_{4} \mathrm{Cl}$ & 24 & Traces & - & - \\
10 & $\mathrm{PhCl}_{11}$ & 24 & Traces & - & - \\
4 & $4-\mathrm{MeOC}_{6} \mathrm{H}_{4} \mathrm{Cl}$ & 24 & No reaction & - & - \\
\hline
\end{tabular}

${ }^{a}$ Reaction conditions: $\operatorname{ArX}(1 \mathrm{mmol})$, phenylboronic acid $(1.5 \mathrm{mmol})$, PdISM catalyst ( $2 \mathrm{mg}, 0.5 \mathrm{~mol} \%$ of $\mathrm{Pd}), \mathrm{K}_{2} \mathrm{CO}_{3}(2 \mathrm{mmol})$, ethanol $(3 \mathrm{~mL}), 100{ }^{\circ} \mathrm{C}$, isolated yields (average of two runs). Time not optimized. TON: turnover number, yield of product/per mol of Pd. TOF: turnover frequency, TON/time of reaction (h)

${ }^{b} \mathrm{PdCl}_{2}$ as catalyst $(0.5 \mathrm{~mol} \%$ of $\mathrm{Pd})$

aryl iodides and furnished the cross-coupled products without evidence of parallel reactions like homocoupling of phenylboronic acid (entries 1-3). The reactivity of the ArBr was similar to that of the aryl iodides but with a longer reaction time (entries 4-7). Entry 6 shows the superiority of the PdISM catalyst when compared to the commercial salt $\left(\mathrm{PdCl}_{2}\right)$; the corresponding product was obtained in almost $3 \times$ higher yield. The ArCl test in the Suzuki-Miyaura cross-coupling is always done to seek a positive result that will actually attest to the competence of the catalytic system, because such halides present great difficulty in making the oxidative addition in the coordinating sphere of Pd (first stage of the catalytic cycle). In the study presented, it is observed that only an activated $\mathrm{ArCl}$ (entry 8 ) achieved a reaction yield where it was possible to isolate the biphenyl, although the yield was low. The other aryl chlorides tested or reacted in the order of trace (entries 9-10) or did not promote the reaction (entry 11). In this study, the TON and TOF values were calculated and proved to be superior (see entry 1 ) to other catalytic systems that employ similar conditions (conventional heating and the same amount of catalyst) [24-26].

In order to compare the results obtained in Table 3 with other studies using the bio-synthesis of palladium nanoparticles, the 4-bromotoluene reaction (entry $6^{a}$ ) was chosen. Thus, observing the isolated yield in 4-methylbiphenyl (97\%), it can be noted that the catalytic system employing PdISM catalyst is superior, in this regard, to the others that employ Hibiscus sabdariffa $\mathrm{L}$. flower extract (90\%) [23], Rosa canina fruit extract (92\%) [11], and Stachys lavandulifolia herbal tea extract (96\%)

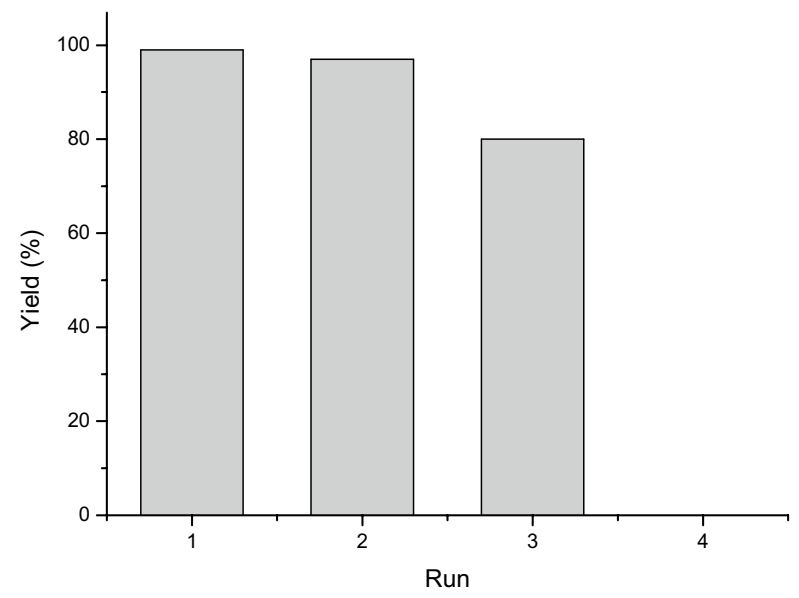

Fig. 5 Yields obtained after 15 min of reaction time in repeated runs of the Suzuki-Miyaura cross-coupling of phenylboronic acid with 4-iodoaniline in ethanol using $\mathrm{K}_{2} \mathrm{CO}_{3}$ as the base and the same load of PdISM catalyst

[13] for the production of Pd NPs. On the other hand, another report that uses black tea leaves (Camellia sinensis) extract for the bio-reduction of Pd was shown to be superior in the production of 4-methylbiphenyl (98\%) [9]. Obviously, each catalytic system has its pros and cons due to the large number of items that must be observed: reaction, Pd load, solvent, base, temperature, time, versatility and availability of biomass used in the synthesis of Pd NPs. Thus, focusing on the results obtained and the availability of biomass, it can be said that the catalytic system reported in this manuscript is among those with potential technological use.

Although the catalyst under study is not supported, it is necessary to evaluate its reusability. Thus, an investigation of the recycling capability of PdISM was conducted with the reaction of 4-iodoaniline with phenylboronic acid (Table 3, entry 1). In the first run, $99 \%$ yield was obtained within $15 \mathrm{~min}$. After the first run, $20 \mathrm{~mL}$ of $\mathrm{Et}_{2} \mathrm{O}$ was added in a Schlenk reactor to extract the organic compounds. The $\mathrm{K}_{2} \mathrm{CO}_{3}$ and PdISM remaining in the reactor were loaded into another reaction. The same procedure was repeated in the other runs. The performance of PdISM in the recycling study can be seen in Fig. 5 .

As shown in Fig. 5, PdISM showed excellent catalytic activity up to the third run (second recycle). Already in the fourth run, no formation of the coupling product was observed. Although the number of recycles is low, it is worth remembering that the catalyst was not supported and no type of stabilizer was used to avoid the agglomeration of the Pd NPs. In this sense, during the fourth run was observed the formation of Pd black deposited in the reactor, this is a strong indication of the catalytic active species agglomeration. 
In order to evaluate the use of the catalytic system developed with PdISM on a gram scale, the 4-bromotoluene reaction was reevaluated (Table 3 , entry $6^{\mathrm{a}}$ ). Thus, the reaction was conducted with an increase of $10 \times$ in the quantities of reagents and base $\left(20 \mathrm{mmol}\right.$ of $\mathrm{K}_{2} \mathrm{CO}_{3}$, $15 \mathrm{mmol}$ of phenylboronic acid, $10 \mathrm{mmol}$ of 4-bromotoluene, and $20 \mathrm{mg}$ of catalyst), $10 \mathrm{~mL}$ of ethanol maintaining the same time and temperature. The average result of two runs indicated $89 \%$ isolated yield in 4-methylbiphenyl, confirming the robustness of the developed catalytic system.

\section{Conclusion}

In conclusion, in this work it was shown, for the first time, the use of llex paraguariensis extract in the bio-reduction of Pd salts to obtain nanometric structures. In addition, the route used was innovative by making use of sonication. The solid obtained, PdISM, was used as a catalyst in Suzuki-Miyaura cross-coupling, composing a new ecofriendly, ligand-free, and low-cost catalytic system. Excellent yields were obtained in the coupling of aryl iodides and bromides with phenylboronic acid. The same catalyst load was able to be recycled $3 \mathrm{x}$. In addition, the PdISM catalyst was able to conduct the reaction of 4-bromotoluene on the gram scale, maintaining a very good performance. Our group continues the study by enabling PdISM support on polymeric films and studying the true catalytically active species.

Acknowledgements This work was supported by grants from CNPq, and FAPERGS (edital FAPERGS/CNPq 12/2014 - PRONEX, protocol 18795.341.30460.15012015), Brazil. The authors would like to thank CEME-SUL FURG for the SEM microscopy analyses.

\section{Compliance with ethical standards}

Conflict of interest On behalf of all authors, the corresponding author states that there is no conflict of interest.

Open Access This article is licensed under a Creative Commons Attribution 4.0 International License, which permits use, sharing, adaptation, distribution and reproduction in any medium or format, as long as you give appropriate credit to the original author(s) and the source, provide a link to the Creative Commons licence, and indicate if changes were made. The images or other third party material in this article are included in the article's Creative Commons licence, unless indicated otherwise in a credit line to the material. If material is not included in the article's Creative Commons licence and your intended use is not permitted by statutory regulation or exceeds the permitted use, you will need to obtain permission directly from the copyright holder. To view a copy of this licence, visit http://creativecommons .org/licenses/by/4.0/.

\section{References}

1. Diederich F, Meijere A (2004) Metal-catalyzed cross-coupling reactions. Wiley-VCHVerlag GmbH\&Co, Weinheim

2. Negishi E (2002) Handbook of organopalladium chemistry for organic synthesis. John Wiley \& Sons, New York

3. Miyaura N, Suzuki A (1995) Palladium-catalyzed cross-coupling reactions of organoboron compounds. Chem Rev 7:2457-2483

4. Reetz MT, Westermann E (2000) Phosphane-free palladium-catalyzed coupling reactions: the decisive role of $\mathrm{Pd}$ nanoparticles. Angew Chem Int Edit 39:165-168

5. Faria VW, Oliveira DGM, Kurz MHS, Gonçalves FF, Scheeren CW, Rosa GR (2014) Palladium nanoparticles supported in a polymeric membrane: an efficient phosphine-free "green" catalyst for Suzuki-Miyaura reactions in water. RSC Adv 4:13446-13452

6. Gholinejad M, Naghshbandi Z, Najera C (2019) Carbon-derived supports for palladium nanoparticles as catalysts for carboncarbon bonds formation. ChemCatChem 11:1792-1823

7. Chinchole AN, Dubey AV, Kumar AV (2019) Bioinspired palladium nanoparticles supported on soil-derived humic acid coated iron-oxide nanoparticles as catalyst for $\mathrm{C}-\mathrm{C}$ cross-coupling and reduction reactions. Catal Lett 149:1224-1236

8. Liu G, Bai X, Lv H (2017) Green synthesis of supported palladium nanoparticles employing pine needles as reducing agent and carrier: New reusable heterogeneous catalyst in the Suzuki coupling reaction. Appl Organometal Chem 31:e3587

9. Lebaschi S, Hekmati M, Veisi H (2017) Green synthesis of palladium nanoparticles mediated by black tea leaves (Camellia sinensis) extract: catalytic activity in the reduction of 4-nitrophenol and Suzuki-Miyaura coupling reaction under ligand-free conditions. J Colloid Interface Sci 485:223-231

10. Khan M, Albalawi GH, Shaik MR, Khan M, Adil SF, Kuniyil M, Alkhathlan HZ, Al-Warthan A, Siddiqui MRH (2017) Miswak mediated green synthesized palladium nanoparticles as effective catalysts for the Suzuki coupling reactions in aqueous media. J Saudi Chem Soc 21:450-457

11. Veisi H, Rashtiani A, Barjasteh V (2016) Biosynthesis of palladium nanoparticles using Rosa canina fruit extract and their use as a heterogeneous and recyclable catalyst for Suzuki-Miyaura coupling reactions in water. Appl Organometal Chem 30:231-235

12. Veisi H, Nasrabadi NH, Mohammadi P (2016) Biosynthesis of palladium nanoparticles as a heterogeneous and reusable nanocatalyst for reduction of nitroarenes and Suzuki coupling reactions. Appl Organometal Chem 30:890-896

13. Veisi $H$, Ghorbani-Vaghei $R$, Hemmati $S$, Aliani MH, Ozturk $T$ (2015) Green and effective route for the synthesis of monodispersed palladium nanoparticles using herbal tea extract (Stachys lavandulifolia) as reductant, stabilizer and capping agent, and their application as homogeneous and reusable catalyst in Suzuki coupling reactions in water. Appl Organometal Chem 29:26-32

14. Veisi H, Faraji AR, Hemmati S, Gil A (2015) Green synthesis of palladium nanoparticles using Pistacia atlantica kurdica gum and their catalytic performance in Mizoroki-Heck and SuzukiMiyaura coupling reactions in aqueous solutions. Appl Organometal Chem 29:517-523

15. Arreche RA, Oca-Vásquez GM, Vega-Baudrit JR, Vázquez PG (2020) Synthesis of silver nanoparticles using extracts from yerba mate (Ilex paraguariensis) wastes. Waste Biomass Valori 11:245-253

16. Grigioni G, Carduza F, Irurueta M, Pensel N (2004) Flavour characteristics of Ilex paraguariensis infusion, a typical Argentine product, assessed by sensory evaluation and electronic nose. J Sci Food Agric 84:427-432 
17. Burris, K.P., Harte, F.M., Davidson, P.M., Neal-Stewart, C. Jr., Zivanovic, S.: Composition and bioactive properties of yerba mate (Ilex paraguariensis A. St.-Hil.): a review. Chil. J. Agric. Res. 72, 268-275 (2012).

18. Filip R, López P, Giberti G, Coussio J, Ferraro G (2001) Phenolic compounds in seven South American Ilex species. Fitoterapia 72:774-778

19. Shamaila S, Sajjad AKL, Ryma NA, Farooqi SA, Jabeen N, Majeed S, Farooq I (2016) Advancements in nanoparticle fabrication by hazard free eco-friendly green routes. Appl Mater Today 5:150-199

20. Castro L, Blazquez ML, Munoz JA, Gonzalez F, Garcıa-Balboa C, Ballester A (2011) Biosynthesis of gold nanowires using sugar beet pulp. Process Biochem 46:1076-1082

21. Saidelles APF, Kirchner RM, Santos NRZ, Flores EMM, Bartz FR (2010) Análise de metais em amostras comerciais de erva-mate do sul do Brasil. Alim Nutr 21:259-265

22. Nadagouda MN, Varma RS (2008) Green synthesis of silver and palladium nanoparticles at room temperature using coffee and tea extract. Green Chem 10:859-862

23. Hekmati M, Bonyasi F, Javaheri H, Hemmati S (2017) Green synthesis of palladium nanoparticles using Hibiscus sabdariffa $\mathrm{L}$. flower extract: Heterogeneous and reusable nanocatalyst in
Suzuki coupling reactions. Appl Organometal Chem. https:// doi.org/10.1002/aoc.3757

24. Alvarenga $G$, Ruas CP, Vicenti JRM, Duarte FA, Gelesky MA, Rosa

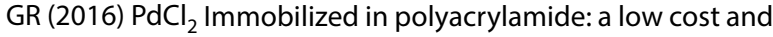
eco-friendly catalyst for Suzuki-Miyaura reactions. J Braz Chem Soc 27:787-793

25. Rosa DS, Vargas BP, Silveira MV, Rosa CH, Martins ML, Rosa GR (2019) On the use of calcined agro-industrial waste as palladium supports in the production of eco-friendly catalysts: Rice husks and banana peels tested in the Suzuki-Miyaura reaction. Waste Biomass Valori 10:2285-2296

26. Schmitt CR, Rosa DS, Vargas BP, Rosa CH, Duarte FA, Scheeren CW, Lopes TJ, Trombetta F, Rosa GR (2018) Coconut agro-industrial waste in the production of catalyst containing palladium: The report of a mini-project for teaching of sustainable SuzukiMiyaura reaction. J Clean Prod 185:342-346

Publisher's Note Springer Nature remains neutral with regard to jurisdictional claims in published maps and institutional affiliations. 